\title{
RESPOSTA DE SOQUEIRAS DE CANA-DE-AÇÚCAR À APLICAÇÃO DE NITROGÊNIO EM SISTEMA DE COLHEITA SEM QUEIMA $\left({ }^{1}\right)$
}

\author{
RENATO DE MELLO PRADO $\left({ }^{2 *}, 4\right)$; MÁRCIO ALEXANDRE PANCELLI $\left({ }^{3}\right)$
}

\begin{abstract}
RESUMO
São restritas as informações sobre a resposta de soqueiras de cana-de-açúcar à aplicação de nitrogênio em colheita sem a despalha a fogo. Diante deste contexto, objetivou-se avaliar a nutrição nitrogenada em soqueiras de cana-de-açúcar, em sistema de colheita sem queima, através de análises químicas do solo, da diagnose foliar, de avaliações biológicas (altura da planta, diâmetro de colmos e número de colmos industrializáveis e da produtividade de colmos). Para esse estudo, instalou-se um experimento em campo, na Fazenda Experimental Santa Terezinha, município de Jaboticabal (SP), em soqueira de cana-de-açúcar cultivar SP 79-1011, em Latossolo Vermelho distrófico, com as doses de nitrogênio: zero; $50 ; 100 ; 150$ e $200 \mathrm{~kg} \mathrm{ha}^{-1}$ de N. Os tratamentos foram aplicados após o corte da canaplanta em junho/2005. Foram avaliados durante os dois primeiros cortes da soqueira de cana-de-açúcar a fertilidade do solo (camadas 0-20 e 20-40 cm), o estado nutricional, o desenvolvimento e a produtividade de colmos. A adubação nitrogenada em soqueira de cana-de-açúcar promoveu acidificação do solo restrita à camada superficial $(0-20 \mathrm{~cm})$; entretanto, não aumentou significativamente os teores de macro e micronutrientes nas folhas, exceto o $\mathrm{N}$ na segunda soqueira. A resposta das duas primeiras soqueiras de cana-de-açúcar à aplicação de nitrogênio, em sistema de colheita sem queima, ocorreu apenas no segundo corte. A dose de $200 \mathrm{~kg} \mathrm{ha}^{-1}$ de $\mathrm{N}$ promoveu aumento no desenvolvimento da cultura, na nutrição da planta e na produtividade de colmos da soqueira da cana-de-açúcar.
\end{abstract}

Palavras-chave: Saccharum officinarum, uréia, nutrição mineral, diagnose foliar, cana-crua.

\section{ABSTRACT \\ SUGARCANE RATOON RESPONSE TO NITROGEN APPLICATION IN A NO BURN HARVESTING SYSTEM}

Information about the responses of sugar cane ratoon to nitrogen application in harvest without the use of fire are restricted. The objective of this work is to evaluate nitrogen nutrition in sugarcane ratoons in harvest without the use of fire through chemical analysis of soil, foliar diagnosis, biological evaluations - plant height, stalk diameter and number of industrialized stalks - and production of stalks. A field experiment was setup at Santa Terezinha Experimental Farm in Jaboticabal (SP), with sugarcane ratoons cv. SP 79-1011, planted in a dystrophic Rhodic Hapludox with nitrogen doses of: zero; 50; 100; 150 and $200 \mathrm{~kg} \mathrm{ha}^{-1}$ of $\mathrm{N}$. The doses were applied after sugarcane harvest in June 2005. During the two cuts of sugarcane ratoon, soil fertility in the layers of 0-20 and 20-40 cm, the plant nutritional condition and the development and production of stalks were evaluated. Nitrogen fertilization of the sugarcane ratoon increased soil acidification only in the superficial layer (0-20), however it didn't raise significantly macro and micronutrients in the leaves, except for $\mathrm{N}$ in the second ratoon. The response of the two first sugarcane ratoons in relation tonitrogen application in harvest without burn occurred only in the second cut. The dose of $200 \mathrm{~kg} \mathrm{ha}^{-1}$ of $\mathrm{N}$ enhanced development of the crop, nutrition of the plant and production of stalks of sugarcane ratoon.

Kew words: Saccharum officinarum, urea, mineral nutrition, foliar diagnosis, green sugarcane harvest.

$\left({ }^{1}\right)$ Recebido para publicação em 19 de janeiro de 2007 e aceito em 9 de maio de 2008.

$\left({ }^{2}\right)$ Departamento de Solos e Adubos, Faculdade de Ciências Agrárias e Veterinária/Unesp, Campus Jaboticabal. Via de Acesso Paulo Donato Castellane, s/n. ${ }^{\circ}, 14884-900$ Jaboticabal (SP). E-mail: rmprado@fcav.unesp.br. $\left(^{*}\right)$ Autor correspondente.

$\left({ }^{3}\right)$ Graduando em Agronomia, Departamento de Solos e Adubos, Faculdade de Ciências Agrárias e Veterinária/Unesp, Campus Jaboticabal.

$\left({ }^{4}\right)$ Bolsista do CNPq. 


\section{INTRODUÇÃO}

O manejo da adubação nitrogenada em canade-açúcar constitui-se fator de produtividade importante especialmente nas soqueiras. O nitrogênio na planta é importante, tendo função estrutural, participando de diversos compostos orgânicos e processos fisiológicos vitais para as plantas (Malavolta et al., 1997). A adubação do $\mathrm{N}$ feita na forma de uréia incrementa o nutriente disponível às plantas, embora possam ocorrer perdas, por lixiviação, que são pouco significativas (Oliveira et al., 2002), e também pode aumentar a acidificação do solo (Maclaren e CAMERon, 1996).

No Brasil, os trabalhos que tiveram por objetivo avaliar a reação das soqueiras à adubação, foram amplamente divulgados na década de 1980. No Estado de São Paulo, Silva e Abramides (1976) relataram que as pesquisas sobre a adubação da canade-açúcar estavam restritas à cana-planta, com poucas informações para as soqueiras. E especificamente com relação à adubação nitrogenada, para a maioria dos Estados canavieiros do Brasil, MARINHO (1974), em Pernambuco e na Paraíba; Azeredo et al. (1984), no Espírito Santo; AzEREDo et al. (1980), em Minas Gerais; Zambello Júnior e Azeredo (1983), Spironello et al. (1987) e Orlando Filho e Zambello Júnior (1983), em São Paulo, relataram que, nos ciclos da cana-soca, a resposta à fertilização nitrogenada foi maior que na cana-planta. Entretanto, outros trabalhos não indicaram efeitos positivos do nitrogênio no rendimento da soqueira de cana-de-açúcar (GALLO et al., 1974, ANjos et al., 1998).

Na revisão de literatura de CANTARELla e RAIJ (1986), na maioria dos experimentos, foram observadas respostas das soqueiras de cana-de-açúcar à aplicação de nitrogênio. Os autores acrescentaram, ainda, que os experimentos sem respostas significativas ao nitrogênio não devem ser interpretados como se em todos esses casos as plantas pudessem prescindir do nutriente.

Nos últimos anos, ocorreram profundas mudanças no sistema de produtividade da cana-deaçúcar, passando da colheita manual com uso da despalha a fogo - cana queimada - à colheita mecanizada - cana crua - atendendo aos aspectos da legislação ambiental que condena o uso da queima de cana-de-açúcar e, também, aos aspectos econômicos, diante do menor custo de colheita mecanizada, cerca de $30 \%$ a $40 \%$ inferior à colheita manual (Oliveira, 2003). Nas áreas sob sistema de cana crua comparado às de cana queimada, o solo possui maior teor de umidade, de matéria orgânica e de alguns nutrientes (Orlando Filho et al., 1998). Desse modo, parte importante do cultivo da cana-de-açúcar da Região
Centro-Sul do País é colhida mecanicamente, atingindo em torno de 39\% (NUNES JúNIOR et al., 2005).

Nesse novo sistema de colheita de cana, as folhas secas, os ponteiros e as folhas verdes são cortados e deixados sobre a superfície do solo, formando uma cobertura morta. No Estado de São Paulo, estima-se que a massa de palhada de cana que permanece sobre o solo após o corte da cana, varie de 13 a $20 \mathrm{t} \mathrm{ha}^{-1}$ de matéria seca (Oliveira et al., 1999). Assim, uma lavoura produzindo $106 \mathrm{t} \mathrm{ha}^{-1}$ de colmos deixará cerca de $15 \mathrm{t} \mathrm{ha}^{-1}$ de palhada (AвRAmo Filho et al., 1993), ou seja, cerca de $1 / 7$ do massa total da cana (colmos + palhada + raízes) permanece na superfície do solo após a colheita. Essa palhada na superfície do solo pode conter, por hectare, cerca de 55 kg de nitrogênio (MANECHINI, 1997); entretanto, é baixa a taxa líquida de mineralização do nitrogênio no período de um ano agrícola (TRIVELIN et al., 1995), atingindo o total de $\mathrm{N}$ acumulado na parte aérea da soqueira, em média, $4 \%$ do $\mathrm{N}$ mineralizado da palhada (GAva et al., 2003).

Esse resíduo vegetal sobre o solo provoca mudanças na dinâmica de nutrientes no solo, exigindo reformulação das práticas até então empregadas no manejo da cana colhida depois de queimada (Costa et al., 2003). Esses autores acrescentam que, com relação ao manejo da adubação, o maior problema é quanto ao uso do nitrogênio na adubação das soqueiras, pois a fonte principal é a uréia e, quando aplicada sobre a palha, verificaramse elevadas taxas de perda de $\mathrm{N}-\mathrm{NH}_{3}$ por volatilização por causa da ação da urease do solo e da palha.

Apesar da importância do nitrogênio para a soqueira da cana-de-açúcar devido à baixa disponibilidade de $\mathrm{N}$ em solos tropicais, os resultados de pesquisa que avaliaram as respostas dessa cultura à aplicação de nitrogênio, em sistemas com emprego exclusivo de colheita sem a despalha a fogo, com emprego da colheita mecanizada, iniciaram-se recentemente, no fim da década de 90 . Resumindo, os experimentos que obtiveram respostas das soqueiras à adubação nitrogenada em sistema de colheita mecanizada são contraditórios, tendo efeito positivo (Costa et al., 2003; VITTI et al., 2007) e também ausência de resposta, como o de Oiticica et al. (1999), que avaliaram a aplicação de nitrogênio (até $60 \mathrm{~kg} \mathrm{ha}^{-1}$ ) com vinhaça, em um Argissolo Vermelho-Amarelo.

Diante deste contexto, o objetivo do trabalho foi avaliar a nutrição nitrogenada em soqueiras de cana-de-açúcar em sistema de colheita mecanizada, através de análises químicas do solo, da diagnose foliar, de avaliações biológicas e da produtividade de colmos. 


\section{MATERIAL E MÉTODOS}

O experimento foi desenvolvido na Fazenda Experimental Santa Terezinha, município de Jaboticabal (SP). Segundo a classificação de Köppen, o clima local é do tipo Cwa subtropical com inverno curto, moderado e seco, verão quente e chuvoso, caracterizando duas estações distintas. O solo é Latossolo Vermelho distrófico, textura argilosa.

O delineamento experimental adotado foi o de blocos casualizados, com cinco tratamentos e quatro repetições. A unidade experimental foi representada pelo cultivo da cultura da cana-de-açúcar (SP 79-1011) de segundo corte, ou primeira soqueira, com parcelas de quatro linhas de $20 \mathrm{~m}$ de comprimento e espaçamento de 1,5 m entre linhas, sendo as duas linhas centrais consideradas úteis. Empregou-se o N na forma de uréia em cobertura incorporada a $10 \mathrm{~cm}$ de profundidade, e a cultura foi colhida manualmente e com a despalha a fogo, atingindo produtividade de colmos médios de $103 \mathrm{t} \mathrm{ha}{ }^{-1}$ e $13,9 \mathrm{t} \mathrm{ha}^{-1}$ de palhada.

Antes da implantação do experimento, foram coletadas 15 subamostras de terra para compor a amostra composta, na camada de $0-20 \mathrm{~cm}$, para a análise química, para fins de fertilidade. O resultado da análise química para fins de fertilidade foi: $\mathrm{pH}=5,5$; M.O. $=23 \mathrm{~g} \mathrm{dm}^{-3} ; \mathrm{P}$ (resina) $=9 \mathrm{mg} \mathrm{dm}^{-3} ; \mathrm{K}=1,2 ; \mathrm{Ca}=33$; $\mathrm{Mg}=12 ; \mathrm{H}+\mathrm{Al}=25 ; \mathrm{SB}=46,2 ; \mathrm{T}=71,2 \mathrm{mmol}_{\mathrm{c}} \mathrm{dm}^{-3}$, e $\mathrm{V}=65 \%$.

Foram estudados os efeitos das doses de 0; 50; 100; 150 e $200 \mathrm{~kg} \mathrm{ha}^{-1}$ de N, considerando-se que 100 $\mathrm{kg} \mathrm{ha}^{-1}$ é a recomendada para a soqueira no Estado de São Paulo, para a produtividade esperada de 80$100 \mathrm{t} \mathrm{ha}^{-1}$ de colmos, segundo SPIRONELLO et al. (1997). O adubo foi aplicado ao lado das linhas da soqueira, de 5 a $10 \mathrm{~cm}$ de profundidade um mês após o corte da cana-planta, em agosto de 2004 (SPIRONello et al.,1997). Para isso, removeu-se parcialmente a palhada próximo à linha e fez-se o sulcamento mecanizado com sulcador acoplado com disco de corte e, em seguida, realizou-se a distribuição manual dos fertilizantes no sulco.

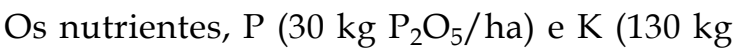
$\mathrm{K}_{2} \mathrm{O} /$ ha), respectivamente, na forma de superfosfato triplo e cloreto de potássio, foram aplicados juntamente com a adubação nitrogenada, de maneira uniforme em todos os tratamentos. As doses foram baseadas na análise química do solo e em função da recomendação de adubação, segundo SPIRONELLO et al. (1997).

O estado nutricional das plantas foi determinado nas amostras de folhas +3 , coletadas aos quatro meses após a brotação da primeira (outubro/ 2004) e da segunda (setembro/2005) soqueiras de cana-de-açúcar, conforme sugerem GALLO (1962) e
Malavolta (1992). As amostras foram secas em estufa de circulação forçada de ar, até obter-se massa constante, e determinados os teores de nitrogênio, bem como os demais macro e micronutrientes, segundo método descrito por BATAGLIA et al. (1983).

Realizou-se a colheita da primeira (junho/ 2005) e da segunda (junho/2006) soqueiras da canade-açúcar, das quais se obteve produtividade de colmos, considerando 4,0 $\mathrm{m}$ linear. Além da produtividade de colmos, foram determinados a altura da planta, o diâmetro do colmo (em 20 colmos/ parcela) e o número de colmos industrializáveis (em duas linhas de 6 metros lineares por parcela).

Foi realizada amostragem de solo (janeiro/ 2005; julho/2005; janeiro/2006) nas camadas de 0-20 $\mathrm{cm}$ e $20-40 \mathrm{~cm}$. A operação foi realizada na entrelinha da cultura, na faixa adubada (cerca de 10 a $15 \mathrm{~cm}$ da linha), a partir de 10 pontos na parcela útil. As determinações analíticas nas amostras de terra, para fins de fertilidade, seguiram os métodos descritos por RAIJ et al. (2001).

Os dados obtidos foram submetidos à análise de variância. Os resultados, cujas médias apresentaram diferenças significativas, foram submetidos à análise de regressão polinomial.

\section{RESULTADOS E DISCUSSÃO}

\section{Efeitos dos tratamentos no solo}

As propriedades químicas do solo, avaliadas aos 6, 12 e 18 meses após a aplicação dos tratamentos, estão relacionadas na tabela 1 . Observa-se que a adubação nitrogenada afetou algumas das variáveis e somente da camada de $0-20 \mathrm{~cm}$, especialmente com a maior dose do nutriente. Na camada superficial, observou-se, aos 6 meses, que a adubação nitrogenada diminuiu apenas o valor $\mathrm{pH}$, e nas demais amostragens, além do $\mathrm{pH}$, houve aumento na concentração do $\mathrm{H}+\mathrm{Al}$, e também diminuição significativa das bases $\mathrm{Ca}$ e $\mathrm{Mg}$, refletindo na soma de bases e na saturação por bases do solo (Tabela 1). Nota-se que a adubação nitrogenada promoveu importante acidificação do solo, apenas com o uso da maior dose de N, ou seja, $200 \mathrm{~kg} \mathrm{ha}^{-1}$ de N. Esses efeitos da adubação nitrogenada, na acidificação do solo, são bastante conhecidos (MACLAREN e CAMERON, 1996) e derivam de reações que produzem $\mathrm{H}^{+}$ (nitrificação).

A lixiviação de nitrato é influenciada diretamente pelos fatores que determinam o fluxo de água no solo e pela concentração de $\mathrm{NO}_{3}{ }^{-}$na solução (White, 1987). 
Tabela 1. Efeitos da adubação nitrogenada em soqueiras de cana-de-açúcar, em algumas propriedades químicas de um Latossolo Vermelho, nas duas camadas e em três épocas após a aplicação dos tratamentos

\begin{tabular}{|c|c|c|c|c|c|c|c|c|c|c|}
\hline $\begin{array}{l}\text { Dose de } \\
\text { Nitrogênio }\end{array}$ & $\begin{array}{c}\mathrm{pH} \\
\left(\mathrm{CaCl}_{2}\right)\end{array}$ & $\begin{array}{l}\text { Matéria } \\
\text { orgânica }\end{array}$ & $\begin{array}{c}\mathrm{P} \\
\text { resina }\end{array}$ & $\mathrm{K}$ & $\mathrm{Ca}$ & $\mathrm{Mg}$ & $(\mathrm{H}+\mathrm{Al})$ & SB & $\mathrm{T}$ & $\mathrm{V}$ \\
\hline $\mathrm{kg} \mathrm{ha}^{-1}$ & & $\mathrm{~g} \mathrm{dm}^{-3}$ & $\mathrm{mg} \mathrm{dm}{ }^{-3}$ & 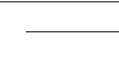 & 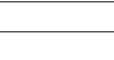 & $\mathrm{mm}$ & $1_{c} \mathrm{dm}^{-3}$ & & & $\%$ \\
\hline \multicolumn{11}{|c|}{ Camada de 0-20 cm - amostragem aos 6 meses } \\
\hline 0 & 5,2 & 22 & 18 & 2,0 & 22 & 8 & 29 & 32,0 & 61,0 & 53 \\
\hline 50 & 5,0 & 24 & 16 & 1,7 & 21 & 7 & 30 & 29,7 & 59,7 & 50 \\
\hline 100 & 4,9 & 23 & 15 & 1,8 & 21 & 7 & 30 & 29,8 & 59,8 & 50 \\
\hline 150 & 5,0 & 22 & 16 & 1,8 & 21 & 7 & 30 & 29,8 & 59,8 & 50 \\
\hline 200 & 4,7 & 23 & 14 & 1,7 & 18 & 6 & 32 & 25,7 & 57,7 & 46 \\
\hline Teste F & $13,53^{* *}$ & $0,39^{\text {ns }}$ & $1,63^{\mathrm{ns}}$ & $2,04^{\mathrm{ns}}$ & $1,46^{\mathrm{ns}}$ & $1,39^{\text {ns }}$ & $0,62^{\text {ns }}$ & $1,47^{\mathrm{ns}}$ & $0,17^{\mathrm{ns}}$ & $1,14^{\mathrm{ns}}$ \\
\hline CV (\%) & 1,8 & 5,8 & 11,0 & 10,4 & 9,8 & 10,8 & 11,0 & 10,3 & 7,4 & 9,2 \\
\hline \multicolumn{11}{|c|}{ Camada de 20-40 cm - amostragem aos 6 meses } \\
\hline 0 & 4,6 & 18 & 6 & 0,6 & 10 & 6 & 34 & 16,6 & 50,6 & 33 \\
\hline 50 & 4,6 & 17 & 6 & 0,6 & 12 & 6 & 35 & 18,6 & 53,6 & 35 \\
\hline 100 & 4,6 & 18 & 6 & 0,6 & 11 & 6 & 37 & 17,6 & 54,6 & 32 \\
\hline 150 & 4,6 & 18 & 6 & 0,6 & 11 & 5 & 31 & 16,6 & 47,6 & 35 \\
\hline 200 & 4,5 & 18 & 6 & 0,6 & 12 & 6 & 36 & 18,6 & 54,6 & 34 \\
\hline Teste F & $0,30^{\mathrm{ns}}$ & $1,07^{\mathrm{ns}}$ & $2,28^{\mathrm{ns}}$ & $0,83^{\mathrm{ns}}$ & $0,22^{\mathrm{ns}}$ & $0,22^{\mathrm{ns}}$ & $0,40^{\mathrm{ns}}$ & $0,18^{\mathrm{ns}}$ & $0,43^{\text {ns }}$ & $0,05^{\mathrm{ns}}$ \\
\hline CV (\%) & 4,3 & 5,4 & 10,5 & 12,9 & 17,2 & 16,2 & 20,3 & 15,3 & 27,5 & 20,9 \\
\hline \multicolumn{11}{|c|}{ Camada de 0-20 cm - amostragem aos 12 meses } \\
\hline 0 & 5,2 & 21 & 13 & 1,3 & 21 & 9 & 29 & 31,3 & 60,3 & 52 \\
\hline 50 & 5,2 & 20 & 10 & 1,2 & 16 & 8 & 30 & 25,2 & 55,2 & 46 \\
\hline 100 & 5,1 & 21 & 12 & 1,2 & 18 & 8 & 28 & 27,2 & 55,2 & 49 \\
\hline 150 & 5,2 & 21 & 12 & 1,2 & 19 & 8 & 30 & 28,2 & 58,2 & 48 \\
\hline 200 & 4,9 & 20 & 12 & 1,3 & 13 & 5 & 32 & 19,3 & 51,3 & 38 \\
\hline Teste F & $4,22^{*}$ & $0,09^{\text {ns }}$ & $0,68^{\mathrm{ns}}$ & $0,28^{\mathrm{ns}}$ & $7,11^{* *}$ & $9,74^{* *}$ & $3,79^{*}$ & $8,87^{* *}$ & $1,12^{\mathrm{ns}}$ & $9,41^{* *}$ \\
\hline CV (\%) & 2,8 & 9,6 & 18,3 & 20,5 & 13,0 & 12,8 & 9,8 & 11,6 & 7,6 & 9,1 \\
\hline \multicolumn{11}{|c|}{ Camada de $20-40 \mathrm{~cm}$ - amostragem aos 12 meses } \\
\hline 0 & 4,8 & 16 & 11 & 0,5 & 10 & 5 & 33 & 15,5 & 48,5 & 32 \\
\hline 50 & 4,9 & 17 & 10 & 0,5 & 10 & 6 & 33 & 16,5 & 49,5 & 33 \\
\hline 100 & 4,8 & 17 & 10 & 0,5 & 9 & 5 & 34 & 14,5 & 48,5 & 30 \\
\hline 150 & 4,7 & 16 & 11 & 0,5 & 9 & 5 & 33 & 14,5 & 47,5 & 30 \\
\hline 200 & 4,7 & 16 & 10 & 0,5 & 8 & 4 & 33 & 12,5 & 45,5 & 28 \\
\hline Teste F & $1,16^{\mathrm{ns}}$ & $1,33^{\mathrm{ns}}$ & $0,23^{\text {ns }}$ & $0,18^{\mathrm{ns}}$ & $1,77^{\mathrm{ns}}$ & $1,47^{\mathrm{ns}}$ & $0,11^{\mathrm{ns}}$ & $1,81^{\mathrm{ns}}$ & $3,08^{\mathrm{ns}}$ & $0,69^{\text {ns }}$ \\
\hline CV (\%) & 3,3 & 5,5 & 27,4 & 12,4 & 13,5 & 18,4 & 7,6 & 13,9 & 3,5 & 13,6 \\
\hline \multicolumn{11}{|c|}{ Camada de $0-20 \mathrm{~cm}$ - amostragem aos 18 meses } \\
\hline 0 & 5,3 & 21 & 19 & 2,1 & 24 & 9 & 27 & 34,1 & 61,3 & 56 \\
\hline 50 & 5,0 & 21 & 16 & 1,4 & 19 & 7 & 30 & 27,2 & 56,7 & 48 \\
\hline 100 & 5,0 & 23 & 14 & 1,6 & 22 & 7 & 30 & 30,3 & 60,6 & 50 \\
\hline 150 & 5,0 & 22 & 16 & 2,0 & 21 & 6 & 30 & 29,3 & 58,8 & 50 \\
\hline 200 & 4,5 & 23 & 15 & 1,7 & 13 & 4 & 41 & 18,5 & 59,0 & 32 \\
\hline Teste F & $12,13^{* *}$ & $2,14 \mathrm{~ns}$ & $0,72 \mathrm{~ns}$ & $2,74 \mathrm{~ns}$ & $9,84^{* *}$ & $16,49 * *$ & $4,54^{*}$ & $11,24^{* *}$ & $0,50 \mathrm{~ns}$ & $11,65^{* *}$ \\
\hline CV (\%) & 3,5 & 6,0 & 28,0 & 30,0 & 12,7 & 14,1 & 15,6 & 12,5 & 8,6 & 11,2 \\
\hline \multicolumn{11}{|c|}{ Camada de 20-40 cm - amostragem aos 18 meses } \\
\hline 0 & 4,7 & 20 & 9 & 0,7 & 13 & 6 & 31 & 20,2 & 51,2 & 40 \\
\hline 50 & 4,8 & 22 & 8 & 0,7 & 14 & 6 & 31 & 20,2 & 51,5 & 40 \\
\hline 100 & 4,7 & 21 & 8 & 0,7 & 14 & 6 & 30 & 20,2 & 50,5 & 40 \\
\hline 150 & 4,7 & 21 & 9 & 0,8 & 13 & 6 & 32 & 19,6 & 51,3 & 38 \\
\hline 200 & 4,6 & 21 & 9 & 1,0 & 11 & 4 & 33 & 15,8 & 48,7 & 33 \\
\hline Teste F & $0,69 \mathrm{~ns}$ & $0,25 \mathrm{~ns}$ & $2,65 \mathrm{~ns}$ & $2,82 \mathrm{~ns}$ & $1,42 \mathrm{~ns}$ & $2,87 \mathrm{~ns}$ & $0,19 \mathrm{~ns}$ & $1,81 \mathrm{~ns}$ & $0,49 \mathrm{~ns}$ & $1,22 \mathrm{~ns}$ \\
\hline CV (\%) & 4,9 & 9,2 & 9,1 & 22,2 & 15,3 & 19,2 & 13,4 & 14,9 & 6,6 & 15,0 \\
\hline
\end{tabular}

ns: não significativo. ${ }^{*}{ }^{* *}$ significativo a $5 \%$ e a $1 \%$ de probabilidade respectivamente. 
É possível que parte do $\mathrm{N}$ lixiviado da camada abaixo de $0-20 \mathrm{~cm}$ seja parcialmente aproveitado pela cana-de-açúcar, pois parte importante do sistema radicular da cultura pode atingir camadas profundas do solo; Ball-CoelHo et al. (1992) observaram que 63\% do sistema radicular da cana-de-açúcar distribuía-se na camada de 0 a $50 \mathrm{~cm}$ de profundidade.

Portanto, os efeitos da adubação nitrogenada nas propriedades químicas do solo são detectáveis apenas à camada superficial $(0-20 \mathrm{~cm}$ de profundidade) e ocorrem de forma mais pronunciada a partir de 12 meses da aplicação do fertilizante nitrogenado.

\section{Efeitos dos tratamentos no estado nutricional}

A adubação nitrogenada não alterou os teores de macro e micronutrientes nas folhas da cana-deaçúcar, tanto no primeiro como no segundo corte da soqueira, exceto do nitrogênio (Tabela 2). Assim, a aplicação de $\mathrm{N}$ incrementou de forma quadrática o teor foliar de $\mathrm{N}$ na primeira $\left(17,1\right.$ ao $\left.18,2 \mathrm{~g} \mathrm{~kg}^{-1}\right)$ e linear na segunda soqueira $\left(15,2\right.$ ao $\left.17,8 \mathrm{~g} \mathrm{~kg}^{-1}\right)$. Segundo Malavolta (1992), são considerados teores médios. Observa-se que a aplicação de $\mathrm{N}$ promoveu concentração no teor de $\mathrm{N}$ na segunda soqueira (15\%), em relação à primeira $(6 \%)$. Essa diferença pode ser decorrente da maior precipitação pluvial acumulada, para os meses que antecederam a colheita (abril a junho), na primeira soqueira $(217,1 \mathrm{~mm})$, comparada à segunda $(24,7 \mathrm{~mm})$. Não foram verificados sintomas de deficiência de $\mathrm{N}$ nas plantas da testemunha, na primeira soqueira $\left(\mathrm{N}=17,1 \mathrm{~g} \mathrm{~kg}^{-1}\right)$, entretanto, na segunda soqueira $\left(\mathrm{N}=15,2 \mathrm{~g} \mathrm{~kg}^{-1}\right)$, verificaram-se os sintomas característicos de deficiência como a clorose das folhas mais velhas. A ausência de sintomas de deficiência nutricional na testemunha da primeira soqueira ocorreu pelo fato de que o teor de $\mathrm{N}$ esteve acima da faixa que poderia induzir esta desordem. Segundo um levantamento do estado nutricional em soqueiras de cana-de-açúcar, realizado pelo IAC em São Paulo, citado por Malavolta et al. (1997), verificou-se que o teor de $\mathrm{N}$ de 10,8 a 16,0 $\mathrm{g} \mathrm{kg}^{-1}$ (folha +3 , aos 4 meses após o corte) é que poderia induzir deficiência de $\mathrm{N}$ na cultura.

Tabela 2. Efeitos da adubação nitrogenada nos teores foliares de macro e micronutrientes, na folha +3 no quarto mês após a corte da primeira e segunda soqueira da cana-de-açúcar

\begin{tabular}{|c|c|c|c|c|c|c|c|c|c|c|c|}
\hline $\begin{array}{l}\text { Dose de } \\
\text { Nitrogênio }\end{array}$ & $\mathrm{N}$ & $\mathrm{P}$ & $\mathrm{K}$ & $\mathrm{Ca}$ & $\mathrm{Mg}$ & $\mathrm{S}$ & B & $\mathrm{Cu}$ & $\mathrm{Fe}$ & Mn & $\mathrm{Zn}$ \\
\hline \multirow[t]{2}{*}{$\mathrm{kg} \mathrm{ha}^{-1}$} & $\longrightarrow$ & + & g & $\mathrm{g}^{-1}$ & 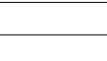 & - & $\longrightarrow$ & 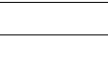 & $\mathrm{mg} \mathrm{kg}^{-1}$ & & \\
\hline & \multicolumn{11}{|c|}{ Primeira soqueira } \\
\hline 0 & 17,1 & 1,4 & 7,5 & 5,8 & 2,5 & 1,2 & 8 & 4 & 178 & 88 & 12 \\
\hline 50 & 17,6 & 1,5 & 7,7 & 5,4 & 2,4 & 1,2 & 8 & 4 & 172 & 90 & 11 \\
\hline 100 & 17,2 & 1,4 & 7,7 & 5,9 & 2,4 & 1,2 & 9 & 4 & 179 & 98 & 12 \\
\hline 150 & 17,8 & 1,4 & 7,7 & 5,6 & 2,3 & 1,2 & 8 & 4 & 212 & 100 & 13 \\
\hline 200 & 18,2 & 1,4 & 7,8 & 5,6 & 2,4 & 1,3 & 9 & 4 & 187 & 122 & 11 \\
\hline Teste F & $3,82^{*}$ & $0,38^{\mathrm{ns}}$ & $0,38^{\mathrm{ns}}$ & $1,49^{\text {ns }}$ & $1,22^{\mathrm{ns}}$ & $0,56^{\mathrm{ns}}$ & $0,76^{\mathrm{ns}}$ & $1,62^{\mathrm{ns}}$ & $0,84^{\mathrm{ns}}$ & $3,07^{\mathrm{ns}}$ & $1,33^{\text {ns }}$ \\
\hline Bloco & $0,50^{\mathrm{ns}}$ & $2,25^{\mathrm{ns}}$ & $3,04^{\mathrm{ns}}$ & $2,23^{\mathrm{ns}}$ & $0,47^{\mathrm{ns}}$ & $3,34^{\mathrm{ns}}$ & $1,07^{\mathrm{ns}}$ & $3,69 *$ & $0,45^{\mathrm{ns}}$ & $0,53^{\text {ns }}$ & $0,35^{\mathrm{ns}}$ \\
\hline R. Linear & $10,28^{* *}$ & - & - & - & - & - & - & - & - & - & - \\
\hline R.Quadrática & $0,92^{* *}$ & - & - & - & - & - & - & - & - & - & - \\
\hline \multirow[t]{2}{*}{ CV $(\%)$} & 2,8 & 5,1 & 4,8 & 6,7 & 6,0 & 5,8 & 8,6 & 7,8 & 18,3 & 15,5 & 11,7 \\
\hline & \multicolumn{11}{|c|}{ Segunda soqueira } \\
\hline 0 & 15,2 & 1,4 & 6,4 & 2,2 & 2,2 & 1,3 & 15 & 5 & 118 & 64 & 15 \\
\hline 50 & 15,6 & 1,4 & 7,4 & 3,0 & 2,4 & 1,3 & 15 & 5 & 118 & 75 & 15 \\
\hline 100 & 16,2 & 1,4 & 6,9 & 3,0 & 2,3 & 1,3 & 15 & 6 & 115 & 77 & 13 \\
\hline 150 & 16,6 & 1,5 & 7,8 & 2,7 & 2,1 & 1,3 & 15 & 5 & 107 & 75 & 16 \\
\hline 200 & 17,8 & 1,4 & 7,1 & 2,8 & 2,3 & 1,2 & 16 & 5 & 122 & 90 & 19 \\
\hline Teste F & $8,50 *$ & $0,86^{\mathrm{ns}}$ & $3,00^{\text {ns }}$ & $1,35^{\mathrm{ns}}$ & $2,89^{\text {ns }}$ & $0,15^{\mathrm{ns}}$ & $0,50^{\mathrm{ns}}$ & $1,19^{\text {ns }}$ & $0,62^{\mathrm{ns}}$ & $2,81^{\mathrm{ns}}$ & $1,08^{\mathrm{ns}}$ \\
\hline Bloco & $1,89^{\text {ns }}$ & $4,52^{*}$ & $7,85^{* *}$ & $14,59 * *$ & $4,96^{*}$ & $0,94^{\mathrm{ns}}$ & $4,75^{*}$ & $0,88^{\mathrm{ns}}$ & $2,15^{\mathrm{ns}}$ & $1,65^{\mathrm{ns}}$ & $0,59^{\text {ns }}$ \\
\hline R. Linear & $32,54^{* *}$ & - & - & - & - & - & - & - & - & - & - \\
\hline R. Quadrática & $0,93^{\mathrm{ns}}$ & - & - & - & - & - & - & - & - & - & - \\
\hline CV $(\%)$ & 4,3 & 7,0 & 7,7 & 20,7 & 5,2 & 9,3 & 5,1 & 23,5 & 12,2 & 14,2 & 25,2 \\
\hline
\end{tabular}

ns: não significativo. ${ }^{*}{ }^{* *}$ significativo a $5 \%$ e a $1 \%$ de probabilidade respectivamente. 
Segundo Malavolta (1992), os teores dos demais nutrientes (Tabela 2) estão dentro da faixa considerada média ou adequada, exceto o $\mathrm{K}$ para as duas soqueiras, o Ca na segunda soqueira e o Zn na primeira soqueira, que estão na faixa considerada baixa.

De forma geral, essas diferenças entre os teores de nutrientes obtidos no trabalho e os da literatura, possivelmente, estão relacionadas às condições edafoclimáticas e de cultivares até o nível de produtividade distinto. Em área de alto potencial produtivo os nutrientes nos tecidos poderiam ser "diluídos". Desse modo, com referência a esse último fator, que é amplamente relatado na literatura, o efeito diluição, ou seja, a concentração dos nutrientes é diluída com o maior crescimento da planta (JARRELL e BEVERLY, 1981).

\section{Efeito dos tratamentos no desenvolvimento e na produtividade de colmos}

Pelos resultados, verificou-se que a aplicação do nitrogênio nas soqueiras de cana-de-açúcar afetou significativamente o desenvolvimento (número de colmos industrializáveis, altura, diâmetro de colmos) e a produtividade de colmos apenas na segunda soqueira (Tabela 3 ).

Tabela 3. Efeitos da adubação nitrogenada no crescimento e desenvolvimento da cana-de-açúcar

\begin{tabular}{lcccc}
\hline Dose & Colmos industrializáveis por metro & Altura & Diâmetro & Produtividade \\
\hline $\mathrm{kg} \mathrm{ha}^{-1}$ & $\mathrm{n}^{.}$ & $\mathrm{m}$ & $\mathrm{mm}$ & $\mathrm{t} \mathrm{ha}^{-1}$ \\
& & & \\
0 & 19,1 & Primeira soqueira & 117,3 \\
50 & 19,2 & 2,40 & 11,3 & 125,6 \\
100 & 19,2 & 2,38 & 11,0 & 116,7 \\
150 & 18,6 & 2,48 & 11,6 & 121,8 \\
200 & 19,0 & 2,48 & 11,3 & 112,2 \\
Teste F & $0,73^{\text {ns }}$ & 2,48 & $0,75^{\text {ns }}$ & $0,68^{\text {ns }}$ \\
Bloco & $2,97^{\text {ns }}$ & $0,02^{\text {ns }}$ & $4,04^{*}$ & $2,82^{\text {ns }}$ \\
CV (\%) & 19,1 & $1,25^{\text {ns }}$ & 10,5 \\
& 3,8 & 5,6 & \\
0 & 15,3 & & 64,63 \\
50 & 16,4 & 1,70 & 66,53 \\
100 & 17,3 & 1,91 & 22,32 & 68,27 \\
150 & 18,3 & 2,09 & 24,94 & 74,15 \\
200 & 17,1 & 2,14 & 26,66 & 72,57 \\
Teste F & 2,12 & 28,02 & $8,90^{* *}$ \\
Bloco & $5,48^{* *}$ & 27,62 & $2,02^{\text {ns }}$ \\
CV $(\%)$ & $1,73^{\text {ns }}$ & $5,34^{*}$ & $17,82^{* *}$ & 13,90 \\
\hline
\end{tabular}

ns: não significativo; *, ** significativo a $5 \%$ e a $1 \%$ de probabilidade respectivamente.

Essa ausência de resposta da primeira soqueira ao $\mathrm{N}$ deve-se possivelmente à maior precipitação pluvial que pode ter elevado as perdas de $\mathrm{N}$ no sistema solo-planta e à resposta da soqueira ao $\mathrm{N}$. As perdas de $\mathrm{N}$ podem ocorrer especialmente por volatização e/ ou lixiviação em áreas de cana-deaçúcar com aplicação de N. Costa et al. (2003) verificaram que as perdas de $\mathrm{N}$ (volatilização) diminui a produtividade da cana-de-açúcar. Alguns autores relataram que a elevada temperatura e a falta de chuva no dia subseqüente à aplicação do fertilizante são importantes componentes de perda do $\mathrm{N}$ via volatilização (HARGROVE, 1988). Essa hipótese de perda de $\mathrm{N}$ por volatilização é amplamente relatada na literatura; entretanto, ela fica enfraquecida no presente experimento, pois o adubo nitrogenado foi incorporado ao solo. Além disso, o $\mathrm{N}$ proveniente da matéria orgânica do solo poderia, com a mineralização, proporcionar incremento do N-disponível à cultura; entretanto, esse fator não foi medido, o que dificulta avaliar a contribuição do N-orgânico do solo na nutrição da cana-de-açúcar. Tem-se que levar em consideração, também, que muitas vezes o erro experimental é elevado em ensaios de campo, não permitindo a detecção de respostas moderadas ao nitrogênio aplicado, resultando em conclusão pela 
não-significância estatística dos aumentos de produtividade observados em função da adição deste elemento (CANTARELla e RAIJ, 1986). Entretanto, não é o caso do presente trabalho, visto que o coeficiente de variação obtido nas variáveis de desenvolvimento e produtividade da primeira soqueira de cana-deaçúcar esteve abaixo de 11\% (Tabela 3).

Desse modo, os resultados no primeiro ciclo de soqueira da cana-de-açúcar, relatando a ausência de resposta da soqueira à aplicação de $\mathrm{N}$, estão em desacordo com SiLVA et al. (1980) e CosTA et al. (2003) e de acordo com os resultados de Urquiaga et al. (1998).

$\mathrm{Na}$ segunda soqueira, observou-se que as doses de $\mathrm{N}$ promoveram incremento quadrático no diâmetro do colmo $\left(y=-0,0002 x^{2}+0,0639 x+22,26\right.$, $\left.\mathrm{R}^{2}=0,99^{* *}\right)$ e linear na altura $(\mathrm{y}=0,0021 \mathrm{x}+1,78$ $\left.\mathrm{R}^{2}=0,80^{* *}\right)$, e de forma quadrática no número de colmos industrializáveis $\left(y=-0,0001 x^{2}+0,0366 x+15,08\right.$, $\left.\mathrm{R}^{2}=0,90^{* *}\right)$. Esse efeito da adubação nitrogenada no desenvolvimento da soqueira da cana-de-açúcar refletiu no aumento de forma linear na produtividade de colmos $\left(y=0,047 x+64,53 R^{2}=0,85^{* *}\right)$ (Tabela 1$)$.

O aumento do número de colmos e seu reflexo direto na produtividade foram relatados por SIMÕES et al (2005), na cana-de-açúcar (SP-80-1842).

Desse modo, os resultados da 2. ${ }^{\text {a }}$ soqueira deste trabalho concordam com os de OrLando Filho et al. (1999) que também indicaram a resposta favorável da aplicação de nitrogênio em soqueiras, sendo a dose de $60 \mathrm{~kg} \mathrm{~N}^{-1}$ superior à testemunha em $20 \%$, enquanto a dose de $120 \mathrm{~kg} \mathrm{~N} \mathrm{ha}^{-1}$ foi superior à testemunha em 35\%. Como houve resposta linear à aplicação de $\mathrm{N}$ na segunda soca de cana-deaçúcar, infere-se que doses maiores que $200 \mathrm{~kg} \mathrm{ha}^{-1}$ podem resultar ainda em incremento de produtividade, pois a extração de $\mathrm{N}$ pelas soqueira é alta $\left(150 \mathrm{~kg} \mathrm{ha}^{-1}\right)$, segundo PRADO et al. (2002); também a eficiência de uso de fertilizantes nitrogenados em soqueiras é relativamente baixa (20\%), especialmente em sistema de cultivo de cana crua, segundo Gava et al. (2005).

A resposta da segunda soca à aplicação de $\mathrm{N}$ poderia ser explicada pelo teor foliar de $\mathrm{N}$, dada a correlação positiva e significativa do teor de $\mathrm{N}$ e a produtividade de colmos (Figura 1). Observa-se que a maior produtividade de colmos esteve associada com o teor de $\mathrm{N}$ igual a $18 \mathrm{~g} \mathrm{~kg}^{-1}$, que está acima do indicado por ReIS JúnIOR et al. (2003), em estudos utilizando o DRIS $\left(13,4 \mathrm{~g} \mathrm{~kg}^{-1}\right)$, e menor que o sugerido como adequado segundo Malavolta et al. (1992) (20$22 \mathrm{~g} \mathrm{~kg}^{-1}$ ). Essas diferenças possivelmente se devem às condições edafoclimáticas distintas e também aos genótipos. Esses resultados indicam também que a folha +3 é adequada para a diagnose foliar em soqueiras de cana-de-açúcar, conforme sugere Malavolta et al. (1992).

Por fim, a produtividade média obtida no experimento, referente à primeira soqueira $(125 \mathrm{t}$ $\left.\mathrm{ha}^{-1}\right)$, foi maior que a segunda $\left(69 \mathrm{t} \mathrm{ha}^{-1}\right)$. A diminuição da produtividade das soqueiras da cana-de-açúcar, ao longo dos cortes, já é conhecida. Este fato ocorre por alguns fatores, como o aumento da densidade do solo e também o déficit hídrico durante o período de maior desenvolvimento da cultura. A primeira hipótese fica enfraquecida, pois na época da colheita do $1^{\circ}$. corte da soqueira, a umidade do solo era baixa, e houve precipitação pluvial em junho de 2005 de apenas $30,1 \mathrm{~mm}$; possivelmente, a densidade do solo não tenha sido afetada, ao passo que a segunda hipótese é a mais provável, pois, de março até junho houve déficit hídrico.

A precipitação acumulada foi baixa no ciclo da segunda soqueira $(161,6 \mathrm{~mm})$, comparada com o mesmo período da primeira soqueira $(345,1 \mathrm{~mm})$. Embora a precipitação pluvial ocorrida na segunda soqueira tenha sido relativamente baixa, entretanto, não comprometeu a resposta da cultura à aplicação de nitrogênio, sendo suficiente para expressar o efeito do nutriente no crescimento da cultura. Entretanto, se a precipitação pluvial fosse elevada nesse cultivo, possivelmente, poderia ter afetado as perdas do nutriente e a produtividade da cultura.

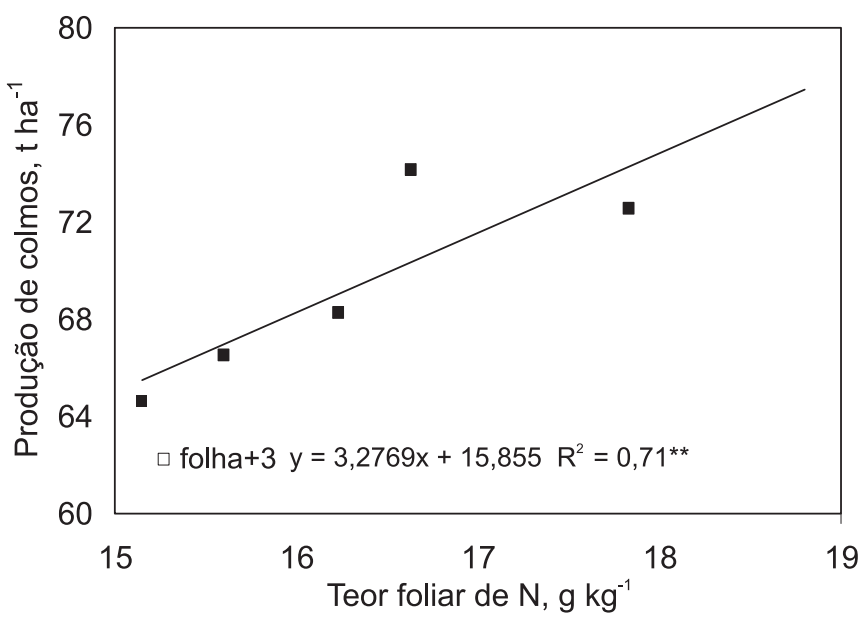

Figura 1. Relação do teor foliar de $\mathrm{N}$ e a produtividade de colmos da segunda soqueira aos quatro meses após o corte. 


\section{CONCLUSÕES}

1. A adubação nitrogenada em soqueira de cana-de-açúcar promoveu a acidificação do solo, restrita à camada superficial $(0-20 \mathrm{~cm})$ e na faixa de aplicação; entretanto, não aumentou significativamente os teores de macro e micronutrientes nas folhas, exceto o $\mathrm{N}$ na segunda soqueira.

2. A resposta das soqueiras de cana-de-açúcar à aplicação de nitrogênio, em sistema de colheita sem queima, ocorreu apenas no segundo corte. A dose de $200 \mathrm{~kg} \mathrm{~N} \mathrm{ha}^{-1}$ na 2 . $^{\text {a }}$ soqueira promoveu incremento no desenvolvimento da cultura, na nutrição da planta e na produtividade de colmos.

\section{AGRADECIMENTOS}

À FAPESP pelo auxílio concedido (Processo 2004/07787-7)

\section{REFERÊNCIAS}

ABRAMO FILHO, J.; MATSUOKA, S.; SPERANDIO, M.L.; RODRIGUES, R.C.D.; MARCHETTI, L.L. Resíduo de colheita mecanizada de cana crua. Álcool \& Açúcar, São Paulo,n.67, p.23-25, 1993.

ANJOS, I.A.; ANDRADE, L.A.B.; FIGUEIREDO, P.A.M. Avaliação do potencial industrial de duas variedades de canade-açúcar (cana-soca) sob diferentes doses de nitrogênio. In: REUNIÃO BRASILEIRA DE FERTILIDADE DO SOLO E NUTRIÇÃO DE PLANTAS, 23., Caxambu, 1998. Resumos... Caxambu: SBCS, 1998. p.87.

AZEREDO,D.F.; MANHÃES, M.S.; ROBAINA, A.A. Adubação nitrogenada em cana-soca. Saccharum-STAB, São Paulo, v.3, n.9, p.35-38, 1980.

AZEREDO,D.F.; ROBAINA, A.A.; ZANOTTI, N. E. Adubação mineral em cana-de-açúcar no Estado do Espírito Santo. Saccharum-STAB , São Paulo, v.7 ,n.30, p.39-43, 1984.

BALL-COELHO, B.; SAMPAIO, E.V.S.B.; TIESSEN, H.; STEWART, J.W.B. Root dynamic in plant ratoon crops of sugar cane. Plant and Soil, Dordrecht, v.142, p.297-305, 1992.

BATAGLIA, O.C.; FURLANI, A.M.C.; TEIXEIRA, J.P.F.; FURLANI, P.R.; GALLO, J.R. Métodos de análise química de plantas. Campinas: IAC, 1983. 48p. (Boletim Técnico, 78)

CANTARELLA, H.; RAIJ, B. Van. Adubação nitrogenada no estado de São Paulo. In: SIMPÓSIO SOBRE ADUBAÇÃO NITROGENADA NO BRASIL, 1984. Ilhéus, Anais... Ilhéus: CEPLAC/SBCS, 1986. p.47-79.

COSTA, M.C.G.; VITTI, G.C.; CANTARELLA, H. Volatilização de $\mathrm{N}-\mathrm{NH}_{3}$ de fontes nitrogenadas em cana-de-açúcar colhida sem despalha a fogo. Revista Brasileira de Ciência do Solo, Viçosa, v.27, n.4, p.631-637, 2003.
GALLO, J.R. Amostragem em cana-de-açúcar para fins de análise foliar. Bragantia, Campinas, v.21, n.54, p.899-921, 1962.

GALLO, J.R.; HIROCE, R.; ALVAREZ, R. Teores de nutrientes nas folhas de cana-de-açúcar (Saccharum officinarum L.) cultivar CB 41/76. Bragantia, Campinas, v.33, p.25-31, 1974.

GAVA, G.J.C., TRIVELIN, P.C.O., VITTI, A.C.; OLIVEIRA, M.W. Balanço do nitrogênio da uréia e da palha de cana no sistema solo-cana-de-açúcar. Pesquisa Agropecuária Brasileira, Brasília, v.40, n.7, p.689-695, 2005.

GAVA, G.J.C.; TRIVELIN, P.C.O.; VITTI, A.C.; OLIVEIRA, M.W. Recuperação do nitrogênio $(15 \mathrm{~N})$ da uréia e da palhada por soqueira de cana-de-açúcar (Saccharum spp.). Revista Brasileira de Ciência do Solo, Viçosa, v.27, n.4, p.621-630, 2003.

HARGROVE, W.L. Soil environmental and management factors influencing ammonia volatilization under field conditions. In: BOCK, B.R.; KISSEL, D.E. (Eds.). Ammonia volatilization from urea fertilizers. Muscle Schoals: Tenessee Valley Authority, 1988. p.17-36. (Bulletin, Y-206)

JARRELL, W.M.; BEVERLY, R.B. The dilution effect in plant nutrition studies. Advances in Agronomy, San Diego, v.34, p.197-224, 1981.

MACLAREN, R.G.; CAMERON, K.C. Soil, plant and fertilizer nitrogen. In: McLAREN, R.G. (Ed.) Soil science: Sustainable production and environmental protection. 2.ed. New York: Oxford University Press, 1996. p.192-207.

MALAVOLTA, E. ABC da análise de solos e folhas: amostragem, interpretação e sugestões de adubação. São Paulo: Agronômica Ceres, 1992.124p.

MALAVOLTA, E.; VITTI, G.C.; OLIVEIRA, S.A. Avaliação do estado nutricional das plantas: princípios e aplicações. $2^{\mathrm{a}}$ ed. Piracicaba: POTAFÓS, 1997.319p.

MANECHINI, C. Manejo da cana crua. In: SEMINÁRIO COPERSUCAR DE TECNOLOGIA AGRONÔMICA, 7., Piracicaba, 1997. Anais... Piracicaba: Copersucar, 1997.p.309327.

MARINHO, M.L. Aspectos agronômicos e econômicos da adubação da cana-de-açúcar em Alagoas. Rio Largo: EECA, 1974. 60p.

NUNES JUNIOR, D.; PINTO, R.S.A.; KIL, R.A. Indicadores de desempenho da agroindústria canavieira: safra 2003-2004. Ribeirão Preto: IDEA, 2005. 195 p.

OITICICA, A.G.R.; MELLO, A.J.P.; MOURA FILHO, G. Resposta da cana-soca a fontes e doses de nitrogênio em área de vinhaça com palhiço da cana crua, variedade RB 83-102. In: CONGRESSO BRASILEIRO DE CIÊNCIA DO SOLO, 27. 1999. Anais... Brasília: SBCS/EMBRAPA, 1999. (CD-Rom)

OLIVEIRA, A.M.S. A relação capital-trabalho na agroindústria sucroalcooleira paulista e a intensificação do corte mecanizado: gestão do trabalho e certificação ambiental. 2003. 219p. Dissertação (Mestrado) - Faculdade de Ciências e Tecnologia, UNESP, Presidente Prudente. 
OLIVEIRA, M.W.; TRIVELIN, P.C.O.; BOARETTO, A.E.; MURAOKA, T.; MORTATTI, J. Lixiviação de nitrogênio, potássio, cálcio e magnésio em solo arenoso cultivado com cana-de-açúcar. Pesquisa Agropecuária Brasileira, Brasília, v.37, n.6, p.861-868, 2002.

OLIVEIRA, M.W.; TRIVELIN, P.C.O.; GAVA, G.J.C.; PENATTI, C.P. Degradação da palhada de cana-de-açúcar. Scientia agricola, Piracicaba, v.56, n.4, p.803-809, 1999.

OLIVEIRA, P.S.R.; ANDRADE, L.A.B.; VALE, F.R.; CARVALHO, G.J. Influência da adubação nitrogenada nas características tecnológicas e rendimento industrial de duas variedades de cana-de-açúcar (ciclo de ano). In: REUNIÃO BRASILEIRA DE FERTILIDADE DO SOLO E NUTRIÇÃO DE PLANTAS, 23. Caxambu, 1998. Resumos... Caxambu: SBCS, 1998. p.94.

ORLANDO FILHO, J.; RODELLA, A.A.; BELTRAME, J.A.; LAVORENTI, N.A. Doses, fontes e formas de aplicação de nitrogênio em cana-de-açúcar. STAB, Piracicaba, v.17,n.4,p.3941, 1999.

ORLANDOFILHO, J.; ROSSETTO, R.; MURAOKA, T.;ZOTELLI, H.B. Efeitos do sistema de despalha (cana crua $x$ cana queimada) sobre algumas propriedades do solo. STAB, Piracicaba, v.16,n.6,p.30-33, 1998.

ORLANDO FILHO, J.; ZAMBELLO, JR., E. Diagnose foliar. In: ORLANDO FILHO, J. (Coord.) Nutrição e adubação da canade-açúcar no Brasil. Piracicaba: IAA-PLANALSUCAR, 1983.p.125-152.

PRADO, R.M., FERNANDES, F.M. e NATALE, W. Calcário e escória de siderurgia avaliados por análise foliar, acúmulo, e exportação de macronutrientes em cana-de-açúcar. Scientia agricola, Piracicaba, v.59, n.1,p.129-135, 2002.

RAIJ, B.van.; ANDRADE, J.C.; CANTARELLA, H.; QUAGGIO, J.A. (Eds.). Análise química para avaliação da fertilidade do solo. Campinas: Instituto Agronômico, 2001. 285p.

REIS JUNIOR, R.A.; MONNERAT, P.H. Validação de normas DRIS para a cultura da cana-de-açúcar. Pesquisa Agropecuária Brasileira, Brasília, v.38, n.3, p.379-385, 2003.

SILVA, J.G.; ABRAMIDES, E. Adubação de soqueira de canade-açúcar. Bragantia, Campinas, v.35, p.35-40, 1976.

SILVA, L.C.F.; ALONSO, O.; ZAMBELLO JUNIOR, E.; ORLANDO FILHO, J. Efeito da complementação mineral da vinhaça na fertilização da cana-de-açúcar. Saccharum -STAB, São Paulo, v.3, n.11, p.40-4, 1980.

SIMÕES, M.S.; ROCHA, J.V.; LAMPARELLI, R.A.C. Indicadores de crescimento e produtividade da cana-de-açúcar. Scientia agricola, Piracicaba, v.62, n.1, p.23-30,2005.

SPIRONELLO, A.; COSTA, A.A.; LANDELL, M.G.A.; PEREIRA, J.C.V.N.A.; IGUE, T.; CAMARGO, A.P.; RAMOS, M.T.B. Adubação NK em três variedades de cana-de-açúcar em função de dois espaçamentos. Bragantia, Campinas, v.46, n.2, p.247$268,1987$.
SPIRONELLO, A.; RAIJ, B. van.; PENATTI, C.P.; CANTARELLA, H.; MORELLI, J.L.M.; ORLANDO FILHO, J.; LANDELL, M.G.A.; ROSSETO, R. Outras culturas industriais. In: RAIJ, B.van.; CANTARELLA, H.; QUAGGIO, J.A.; FURLANI, A.M.C. Recomendações de adubação e calagem para o Estado de São Paulo. 2.ed. Campinas: Instituto Agronômico, 1997. p.237-239. (Boletim técnico, 100)

TRIVELIN, P.C.O.; VICTORIA, R.L.; RODRIGUES, J.C. Aproveitamento por soqueira de cana-de-açúcar de final de safra do nitrogênio da aquamônia $-{ }^{15} \mathrm{~N}$ e aplicado ao solo em complemento à vinhaça. Pesquisa Agropecuária Brasileira, Brasília, v.30, n.12, p.1375-1385, 1995.

URQUIAGA, S.; ALVES, B.J.R.; BODDEY, R.M.; OLIVEIRA, O.C.; RESENDE, A.S.; WEBER, H. Efeito da queima, aplicação de $\mathrm{N}$, irrigação e molibdênio na produtividade e acumulação de nitrogênio na cana de açúcar a longo prazo. Seropédica: Embrapa Agrobiologia, 1998. 13p. (Embrapa-CNPAB. Documentos, 72)

VITTI, A.C.; TRIVELIN, P.C.O.; GAVA, G.J.C. Produtividade da cana-de-açúcar relacionada ao nitrogênio residual da adubação e do sistema radicular. Pesquisa Agropecuária Brasileira, Brasília, v.42, p.249-256, 2007.

WHITE, R.E. Leaching. In: WILSON, J.R. Advances in nitrogen cycling in agricultural ecosystems. Wallinggord: C.A.B. International, 1987. p.193-211.

ZAMBELLO JÚNIOR, E.; AZEREDO, D.F. Adubação na Região Centro-Sul. In: ORLANDO FILHO, J. (Coord.). Nutrição e adubação da cana-de-açúcar no Brasil. Piracicaba: IAA/ Planalsucar, 1983. p.287-313. 